\title{
Escape to Lateral Buccal Cavity/Floor of Mouth
}

National Cancer Institute

\section{Source}

National Cancer Institute. Escape to Lateral Buccal Cavity/Floor of Mouth. NCI

Thesaurus. Code C127191.

A finding of escape to lateral buccal cavity/floor of mouth during swallowing. 